\title{
THE EPISTEMIC CONNECTION BETWEEN KNOWLEDGE AND EXPERIENCE
}

\author{
SCOTT D. PALMER
}

Last year it was my privilege to address this conference on the subject of 'Foundationalism, Coherentism, and Epistemic Ultimates.' At that time I contended that foundationalism--the view that a necessary condition for the justification of any empirical proposition is that it rest, wholly or partly, on some epistemically ultimate 'selfjustifying' proposition(s)--could not be correct, because the epistemically ultimate propositions it requires are impossible. Through some relatively straightforward arguments, I attempted to show that such propositions (a) could not be justified themselves without some reliance on still prior propositions, and (b) could not be adequate in content to provide for the justification of the rest of our knowledge.

I come before you today, hat in hand--not exactly to recant, but to admit that my foundationalist opponents had a better case than I was willing to give them credit for at the time. The key insight of foundationalism--an insight to which coherentists must pay homage--is that our judgments must someliow be connected with our sub-judgmental experience of the world. The fact that foundationalists have been unable to embody this insight in a defensible theory should not lead us to abandon the insight itself.

One more preliminary comment is in order, and then we can get down to business. Coherentism, the view which I advocate in opposition to foundationalism, holds that propositions are justified by having a relation of logical coherence with a system of thought. A proposition $p$ is coherent with a system $s$, somewhat: loosely, if it does not conflict with any other proposition(s) of $s$ or any deductive consequence of the 
proposition(s) of $s$; and if it gives logical (not necessarily deductive) support to at least some of the other members of $s$, and receives logical (not necessarily deductive) sypport from at least some of the other members of $S$. Preliminaries now out of the way, let's move on to the main issue at hand.

That there is some sort of raw experience, a 'given' element which underlies our judgments, I have no doubt. Moreover, this given element constrians the system of judgments which we articulate. But how? How is it that when I feel a pain, I am 'justified' in recognizing it as a pain but not as a tickle? The mental sequence seems to go like this:

[1] sub-judgmental experience: 'pain.'

[2] elementary judgment of perception: recognition of the 'pain' as a pain.

(3) explicit judgment: "I have a pain."

Now of course in the adult mind this sequence is virtually instantaneous; but I think it captures the logical order of things.

It's fairly clear that [3], the explicit judgment that "I have a pain," is justified at least in part on the basis of $|2|$, the implicit judgment involved in recognizing the pain as a pain. But how can we justify our step from [1] to $\overline{[2]}$ ? If we construe justification as a quasi-logical relation which can only obtain between judgments, then we simply camnot justify the step from [1] to [2]. But we must justify it somehow, or our knowledge will be completely severed from our experience. There will be no more reason for me, upon having a 'painful' experience, to judge that $I$ an in pain than for me to judge that $I$ an the King of Siam; and this is intolerable.

This is the point that foundationalists and truthas-correspondence theorists have been trying to make: and I think they're right. Our knowledge must be tied to our experience somehow. But how?

The most obvious way of attacking the problem is to revise our notion of the justification-relation. If we colld allow elementary judgments of perception to be justified on the basis of sub-judgmental units of 'bare experience,' then oll problem would be solved. On having a sub-judgmental experience of 'pain' (level $|1|)$, we would then be justifjed in making the perceptual judgment which consists of recognizing the 
'pain' as pain (level [2]). We would have bridged the gap between our system of bare experiences and our system of judgments. This is the approach which, it seems to me, is unconsciously taken by many foundationalists.

A typical foundationalist formulation involving this type of justification is given by Roderick Chisholm:

If a person believes, without ground for doubt, that he is perceiving something to be F, then it is evident (justified) for him that he perceives something to be $F$.

This sounds fine, and is even true, but it doesn't solve our problem. 'Perceiving something to be $F$ ' and 'believing that one perceives something to be F' hardly qualify as bare experiences: they sound much more like perceptual judgments of levels [2] and [3]. And yet Chisholm has captured, as well as possible, the foundationalist approach to tying judgment to experience. The difficulty is that as soon as we bring the 'bare experience' of F-ness into the realm of language, it ceases to be bare; as soon as we tack the label ' $F$ ' onto an experience, it has been classified and brought within a system of judgments. What Chisholm seems to be telling us is that if we have arrived at level [2], the level of implicit perceptual judgment, then we are justified in moving on to level [3] and making out implicit judgment explicit. But we

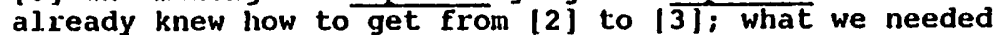
was to get from [1] to [2].

I don't mean to pick on chisholm--I probably couldn't do any better than he did with that kind of principle myself. But no principle of this type can ever do the job of connecting our judgments to our experience: it can only connect higher-level judgments to lower-level ones. There is no way to set up a justification-relation by which an ex hypothesi logically characterless bare experience could warrant or constrain a judgment in any way. We would always be left in the situation of making elementary judgment $x$ because . . Because what? As long as the right-hand term of the justification-relation is supposed to be a bare experience there can be no answer, because any answer we give will inevitably be a judgment.

Now we come to the interesting part. If we cannot set up a direct justifying link between knowledge and experience, then we had better try to set up an 
indirect link. Otherwise, all is lost and we are living in a dream world.

I have on occasion shocked people at parties by saying that I thought wittgenstein, in the latter part of his life, was a crypto-coherentist and incipient Absolute Idealist. I am even more convinced of this now. Some of his ideas give us a way out of our predicament.

Wittgenstein said a lot of really strange things, but two of the strangest--and most important for our purposes--are the following:

[i] that I cannot know that I am in pain. I can, however, know that other people are in pain.

[ii] that initial indoctrination in a language-system is not education, but training.

What I wish to maintain, taking my cue from these theses of Wittgenstein's, is that what links bare experiences to elementary 'judgments' of perception is not judgment, but association. I would suggest that elementary judgments of perception are judgments only in a special sense, which will be explored in what follows.

Consider the way that we learn language in the first place. Our parents hold a red thing before us and say the word 'red;' this procedure is repeated over and over, and when we finally utter the sound 'red' upon being presented with a red thing, we are rewarded with a sweet. In this way a linguistic 'peg' is established. We do not know that a red thing is red, but we associate the quality redness with the linguistic peg.

Before proceeding any further, it is necessary to give a brief account of what 'association' is to mean in this context. One might object to my thesis about linguistic pegs that a child would need to recognize the red thing for what it was before he could associate it with the sound 'red.' Ihen, he would remember that in the past this particular color-quality had been presented at the same time as a particular sound, viz, 'red.' So, it might be maintained, even by invocation of association and linguistic pegs does not really solve our problem of getting from level |1| to level 
[2] after all, since it presupposes that we are already operating with level [2] implicit judgments.

This objection can be met by distinguishing between ordinary memory and what I call quasi-memory is unconscious, automatic, and sub-judgmental. For example, when I am remembering a melody, I do not need to consciously think ahead and 'remember' what the next note is supposed to be: my consciousness glides effortlessly and automatically from one note to the next. Association, as it applies to sense-qualities and linguistic pegs, is a form of quasi-memory. It is a relation which obtains between two contents of consciousness when the presence of one immediately elicits the idea (here meant in Hume's sense of a faint mental 'image' of the appropriate perceptual type) of the other. Thus, the association between a sensequality, e.g. red, and a sound-word, 'red,' need not depend on any prior judgments, implicit or otherwise. When the child is presented with a red object, his consciousness glides automatically--with no thought on his part--to the idea of the sound-word 'red.'

Now, at the extremely low level of a child who has just learned the word 'red,' judgment is not yet present. The child does not know that a red thing is red; all he 'knows' is that saying the sound 'red' when presented with a red thing resulted in getting a sweet (and he 'knows' this only by quasi-menory). But as the child continues to experience and learn, his world becomes richer. He acquires linguistic pegs for more experiences, and begins to learn linguistic pegs for the relations between these experiences--e.g.. that this 'red'-experience is 'behind' that 'green'experience; or that a 'red'-associated experience never occurs at the same time and position in his perceptual field as a 'green'-associated experience. And eventually, mirroring in his consciousness the structure which he finds in his experience, he realizes that a 'red'-experience is distinct from a 'green'experience--i.e., he acquires rudimentary concepts of identity and difference--depending, as before, on quasi-memory. Further, at some point it dawns on him that the 'red'-experience is sometimes present, and sometimes not--thereby acquiring rudimentary concepts of presence and absence.

It is within the context of the child's rudimentary concepts of identity and difference, presence and absence, that the essential form of judgment--that one thing is another--arises. The preceding account is, of 
course, rather sketchy, but I think it captures the essence of what goes on.

Let us now return more specifically to the question about our most elementary judgments of perception. What I wish to maintain is that in one respect they are judgments, but that in another respect they are mere associations. As the child's awareness of the world broadens, he arranges the mental representations of the sound-words he has learned into a formal structure isomorphic to that which he finds in his experience. This formal structure is a system of thought in embryo.

With the advent of the formal mental representation of the structure of the child's experience, the soundword 'red' has come to be associated with two things. on the one hand, it is associated with the redexperience. But on the other hand, it has now becone associated with a place in a formal system of mental representations of sound-words. It is in this latter association that the elementary judgment of perception really becomes a judgment.

As the formal structure becomes more and more completely articulated--with more words for qualities, spatial and temporal relations, etc.--there will be certain arrangements of words which are possible and certain arrangements which are not: these possibilities and impossibilities mirroring those found in the child's experiencs. Then, when the child associates the word 'red' 2 with a red thing, the association will fit in harmoniously with the rest of his associations. For example, consider the following:

$$
\begin{aligned}
& \text { association } \# 1 \text { : 'this-red' } \\
& \text { association } \# 2 \text { : 'this-same-that' } \\
& \text { association } \# 3 \text { : 'that-red' }
\end{aligned}
$$

But consider another case:

$$
\begin{aligned}
& \text { association \#1: 'this-red' } \\
& \text { association \#2: 'this-same-that' } \\
& \text { association \#3: 'that-green' }
\end{aligned}
$$

since in experience a red and a green cannot occupy the same position in a perceptual field at the same time, the second set of associations is in conflict, i.e.. is incoherent.

We now have, no longer a mere association of an experience with a sound-word, but an elementary judgment of perception. We have a mental unit which is 
connected to 'bare experience' but which can also be tested for truth or falsity by virtue of its position in a formal system. And the test involved is colierence!

'T'uus, we have done what we set out to do. We have provided a 1 ink between knowledge and experience such that elenentary judgments of perception are justified, albeit not quite in the way we had expected.

Unsolved problens: To really go through, the preceding account must be supplemented by more complete theories of memory and quasi-memory, the nature of judgment, and a more explicit account of just exactly how judgment arises out of a hodge-podge of quasimenory associations. These questions will provide the most interesting 3 and challenging issues in the months and years to come.

Indiana University 
NO'IES

$1_{\text {of }}$ course, the more comprehensive the system, the more justification a proposition can derive from it. Also, the more lines of support going from the proposition to the system and vice versa, the more 'coherent' the proposition is with the system and the more justification it receives.

${ }^{2}$ Note that, with the advent of the formal system, it is no longer necessary to speak strictly of 'soundwords'--the sound-words have become words by virtue of having a place in a formal system.

${ }^{3}$ After I circulated a copy of this paper for comments, Mark Pastin pointed out that Wilfrid Sellars--in a 1954 paper, 'Some Reflections on Language Games'--had, um, shall we say, anticipated certain features of my theory. I have since then read the Sellars paper, find it highly illuminating, and recommend it to everyone with an interest in this issue. It is reprinted in Sellar's science. Perception and Reality, pp. 321-58. 